\title{
Hipoplasia dérmica focal (síndrome de Goltz)
}

\author{
Guadalupe X. Corona-Guerra ${ }^{1 *}$ y Marisol Ochoa-Apreza ${ }^{2}$ \\ ${ }^{1}$ Servicio de Pediatría; ${ }^{2}$ Servicio de Dermatología Pediátrica. Hospital General de San Juan del Río, Querétaro, México
}

\section{Resumen}

Introducción: La hipoplasia dérmica focal o síndrome de Goltz es una rara genodermatosis de herencia dominante ligada al $X$, que afecta al tejido proveniente de las placas del ectodermo y del mesodermo. El cuadro clínico se caracteriza por alteraciones cutáneas, oftálmicas, neurológicas, dentales, ungueales, bucales, de tejidos blandos y esqueléticas. El diagnóstico se realiza por los hallazgos clínicos en un individuo con alteraciones ectodérmicas y malformaciones características en las extremidades. El manejo es multidisciplinario y, al igual que el pronóstico, depende de las alteraciones específicas que presente cada paciente. Caso clínico: Se presenta el caso de un recién nacido de sexo femenino, de 15 días de vida, con zonas de alopecia en piel cabelluda, herniación de tejido celular subcutáneo en varias áreas de todos los segmentos corporales, escotadura en ala nasal, hendidura en encía superior, defecto grave de extremidad superior izquierda con rizomelia (acortamiento de segmento proximal) y aplasia de radio, así como ectrodactilia de miembro pélvico derecho. Todos los hallazgos son compatibles con hipoplasia dérmica focal de acuerdo con los criterios diagnósticos. Conclusiones: Se presenta el caso de una paciente recién nacida con síndrome de Goltz.

Palabras clave: Hipoplasia dérmica focal. Síndrome de Goltz. Atrofia de piel. Ectrodactilia. Displasia ectodérmica.

\section{Focal dermal hypoplasia (Goltz syndrome)}

\section{Abstract}

Background: Focal dermal hypoplasia or Goltz syndrome is a rare X-linked dominant inherited genodermatosis, affecting both the ectodermal and mesodermal tissue. Clinical manifestations include skin abnormalities, defects in eyes, teeth, nails, mouth, soft tissues and skeleton. The diagnosis is based on clinical findings and is suspected in individuals with ectodermal abnormalities and characteristic malformations in the extremities. The management is multidisciplinary and, like the prognosis, depends on the specific alterations that each patient presents. Case report: We report the case of a 15-day-old female newborn with alopecic areas on the scalp, herniation of subcutaneous cellular tissue at the lumbar level, nasal wing notch, severe left superior limb defect with rhizomelia (proximal segment shortening) and radio aplasia, as well as right leg ectrodactyly, areas of atrophy compatible with focal dermal hypoplasia according to diagnostic criteria. Conclusions: We present a case of female newborn patient with Goltz syndrome.

Key words: Focal dermal hypoplasia. Goltz syndrome. Skin atrophy. Ectrodactyly. Ectodermal dysplasia.

\section{Correspondencia:}

${ }^{\star}$ Guadalupe X. Corona-Guerra

E-mail: ximen9coro@ hotmail.com
Fecha de recepción: 15-09-2017

Fecha de aceptación: 27-02-2018

DOI: 10.24875/BMHIM.M18000025
Disponible en internet: 14-05-2018 Bol Med Hosp Infant Mex. 2018;75:178-182 www.bmhim.com

1665-1146/@ 2018. Hospital Infantil de México Federico Gómez, impreso por Permanyer México SA de CV, todos los derechos reservados. 


\section{Introducción}

El síndrome de Goltz (hipoplasia dérmica focal) es una genodermatosis poco frecuente que incluye alteraciones en distintos órganos, provenientes del mesodermo y ectodermo. Esto se debe a mutaciones en el gen PORCN, localizado en el cromosoma $X$, que es sustancial para el adecuado desarrollo de estas placas embrionarias. Las malformaciones sistémicas incluyen alteraciones dentales, esqueléticas, neurológicas, oculares, cardiacas, renales y genitourinarias, entre otras ${ }^{1}$. El síndrome de Goltz afecta principalmente al sexo femenino, con un $90 \%$ de los casos reportados en mujeres, como resultado de un patrón de herencia dominante ligado al cromosoma $X^{2}$. Debido a este tipo de herencia, es letal en los pacientes de sexo masculino; aquellos que lo presentan pueden ser casos secundarios a un mosaicismo poscigótico ${ }^{1}$. Goltz fue el primer médico en describir esta condición, en 1962, tres casos en mujeres con hipoplasia dérmica, herniación del tejido graso y defectos mesoectodérmicos ${ }^{3,4}$.

La principal característica de este síndrome es el adelgazamiento de la dermis, que produce lesiones lineales deprimidas y herniaciones de la grasa subcutánea. Como hallazgos asociados se pueden encontrar otras anomalías, como papilomas en las mucosas o la piel, telangiectasias lineales, uñas distróficas, alopecia, urticaria y fotosensibilidad.

La hipoplasia dérmica focal es un trastorno poco común, con cerca de 300 casos reportados de individuos afectados en todo el mundo; la prevalencia exacta se desconoce $e^{1,4,5}$.

En este artículo se presenta el caso de una recién nacida con hipoplasia dérmica focal (síndrome de Goltz).

\section{Caso clínico}

Lactante de 15 días de vida, referida del medio privado al Hospital General de San Juan del Río, en Querétaro, para su estudio por síndrome dismórfico. Dentro del interrogatorio se encuentra lo siguiente: antecedentes heredofamiliares negados, producto de la gesta 3, aborto 1 (octubre 2011, se desconoce la causa), cesáreas 2 (una niña de 4 años clínicamente sana y la actual). Hija de madre de 34 años, padre de 36 años, sin consanguinidad, producto de embarazo normoevolutivo, con adecuado control prenatal. Durante el embarazo no se reportaron alteraciones congénitas aparentes (estudio por vía abdominal por oligohidramnios secundario a rotura prematura de membranas); se encontró baja reserva fetal y datos de restricción en el crecimiento intrauterino. Al nacer, la paciente presentó APGAR 8/9, peso de $2100 \mathrm{~g}$ (bajo para la edad gestacional), talla de $45 \mathrm{~cm}$, Capurro de 37 semanas y perímetro cefálico de $30 \mathrm{~cm}$.

En la exploración física se evidencian múltiples anomalías congénitas: microcefalia, dermatosis diseminada a todos los segmentos corporales, alteraciones en los pabellones auriculares, escotadura en ala nasal, defecto grave de extremidad superior izquierda con rizomelia (acortamiento del segmento proximal) y aplasia de radio y sindactilia, así como ectrodactilia de miembro pélvico derecho.

La dermatosis de la paciente se encontró diseminada a todos los segmentos corporales: piel cabelluda, cuello, tórax anterior y posterior, abdomen y diversas caras de las extremidades; caracterizada por múltiples zonas de atrofia de la piel, algunas ulceradas y con eritema, telangiectasias, herniación del tejido celular subcutáneo a nivel lumbar de $0.5 \mathrm{~cm}$ de diámetro y alopecia en piel cabelluda; lesiones aparentemente asintomáticas para la paciente y presentes desde el nacimiento.

Dentro del abordaje diagnóstico se solicitaron los siguientes estudios: ecocardiograma, en el cual se detectó un conducto arterioso pequeño y comunicación interatrial en foramen oval de $4 \mathrm{~mm}$; valoración oftalmológica, sin alteraciones evidentes; y radiografía de extremidad superior izquierda, con rizomelia y agenesia de radio en el miembro torácico izquierdo; radiografía de extremidad inferior derecha que confirmó la ectrodactilia; ultrasonido renal, con ectasia renal izquierda; tomografía computada (TC) de cráneo simple, con edema leve; TC de columna, con presencia de disrafismo espinal cerrado a nivel torácico, sin presentar espina bífida; y cariotipo, reportado como 46XX. Se realizó biopsia incisional, translesional, de piel afectada y sana. El reporte de la piel afectada confirmó epidermis con atrofia focal, con presencia de dos a tres capas de queratinocitos e hipoplasia de la dermis, con muy escasas fibras de colágeno, casi continuándose inmediatamente con el tejido celular subcutáneo. La piel perilesional se reportó sin alteraciones.

Se sospechó un síndrome de Goltz por los hallazgos clínicos y paraclínicos. De acuerdo con los criterios mayores y menores que se muestran en la tabla 1 , se confirmó el síndrome de Goltz por zonas de alopecia y atrofia dérmica en piel cabelluda (Fig. 1), atrofia de la dermis en tórax y abdomen anterior, ectrodactilia en miembro pélvico derecho (Fig. 2), herniación grasa nodular a nivel lumbar (Fig. 3), rizomelia y agenesia de radio en miembro torácico izquierdo, y sindactilia. La atrofia de la epidermis y la hipoplasia de la dermis se corroboraron con estudio de patología (biopsia de piel) (Fig. 4). 
Bol Med Hosp Infant Mex. 2018;75

Tabla 1. Criterios clínicos para diagnóstico de hipoplasia dérmica focal y porcentaje de presentación

\section{Criterios mayores}

Manifestaciones ectodérmicas

Atrofia y áreas de hipoplasia de piel que siguen las líneas de Blaschko

Áreas de piel hipopigmentadas o hiperpigmentadas

$90-100 \%$

Herniación nodular grasa

$60-70 \%$

Uñas hipoplásicas o displásicas

$80-90 \%$

Telangiectasias

$80 \%$

Malformaciones de extremidad

Sindactilia

$70-90 \%$

Ectrodactilia

Oligodactilia

$20-40 \%$

Ausencia congénita de mano, brazo, antebrazo, codo sin porciones distales, aqueiria o hemimelia

Acortamiento de huesos largos

$50-80 \%$

\section{Criterios menores}

Manifestaciones ectodérmicas

Alopecia, cabello quebradizo

$80 \%$

Papiloma verrugoso en mucosas (boca, nariz, laringe, esófago, vagina, recto)

Anomalías dentales, incluyendo defectos en el esmalte

$80 \%$

Alteraciones en el cabello por microscopía electrónica

$80-90 \%$

Otras manifestaciones

Coloboma de iris

$50 \%$

Coloboma coriorretinal

$60 \%$

Microftalmia y anoftalmia

$10-45 \%$

Catarata

$10 \%$

Nistagmo

$30 \%$

Estrabismo

$20 \%$

El diagnóstico se realiza con tres o más criterios mayores de manifestaciones ectodérmicas y al menos un criterio de malformación de extremidad.

Durante su estancia hospitalaria, la paciente cursó con sepsis neonatal temprana, por lo que fue manejada con antibióticos intravenosos. No se han identificado hasta el momento alteraciones gastrointestinales ni del sistema nervioso central. La paciente fue egresada a su domicilio, con seguimiento multidisciplinario.

\section{Discusión}

Este caso ilustra la presentación clínica de una paciente recién nacida con síndrome de Goltz (hipoplasia dérmica focal). Las manifestaciones varían entre los individuos afectados, y muchos tienen solo un subconjunto de los rasgos característicos ${ }^{6}$. Las lesiones, como en este caso, están presentes desde el nacimiento, y su expresividad es variable. El pronóstico y el tratamiento dependen de los órganos comprometidos. La mayoría de los individuos que padecen hipoplasia dérmica focal suelen tener estatura baja desde el nacimiento. El desarrollo es normal, aunque el 15\% de los casos reportados presentan deterioro cognitivo, pero solo en aquellos que implican mayor gravedad ${ }^{1,7}$. 


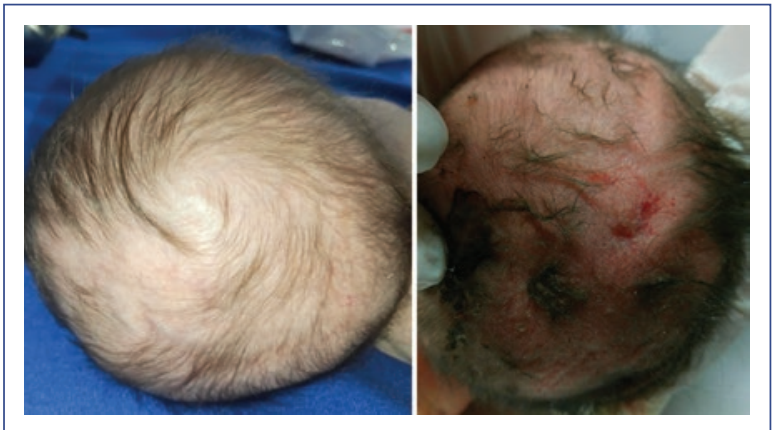

Figura 1. Zonas de alopecia e hipoplasia de la dermis a los 15 días de vida (izquierda) y al mes de vida (derecha).

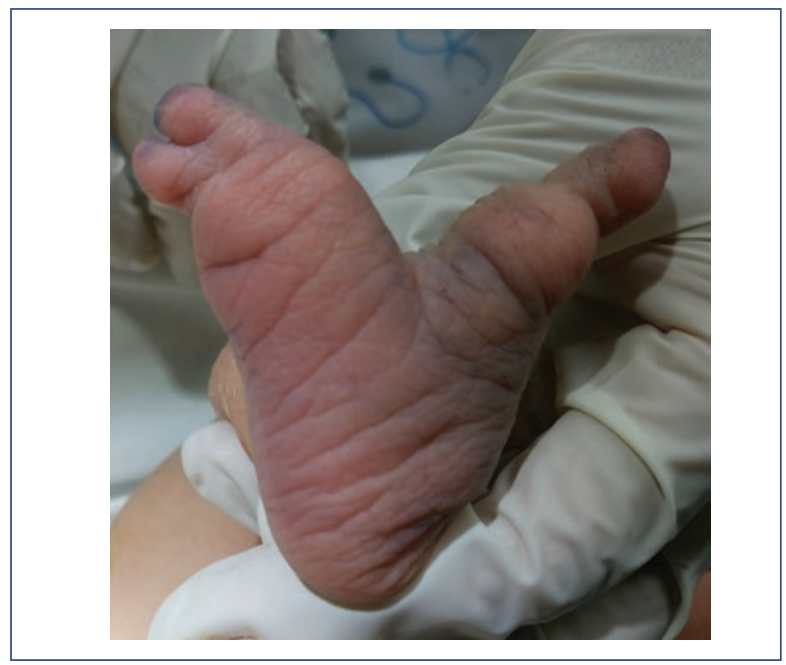

Figura 2. Ectrodactilia en pie derecho.

Raramente se han reportado anormalidades estructurales del cerebro y la espina bífida; también se han detectado crisis convulsivas ${ }^{8}$.

Las lesiones cutáneas más características en los pacientes con este síndrome son lineales o reticulares y siguen las líneas de Blaschko, con atrofia cribiforme, rojizas o rojo-amarillentas, hiperpigmentaciones e hipopigmentaciones en sitios atróficos, y telangiectasias. Las áreas más frecuentemente comprometidas son el tronco y las extremidades, pero puede afectarse cualquier zona del tegumento. Otros hallazgos cutáneos incluyen nódulos lipomatosos en áreas atróficas y papilomas múltiples con apariencia de frambuesa en sitios de unión entre piel y mucosas (incluyendo la boca, la nariz, la laringe, el esófago, y la mucosa vaginal o rectal), que no están presentes al nacimiento, sino que aparecen en los primeros

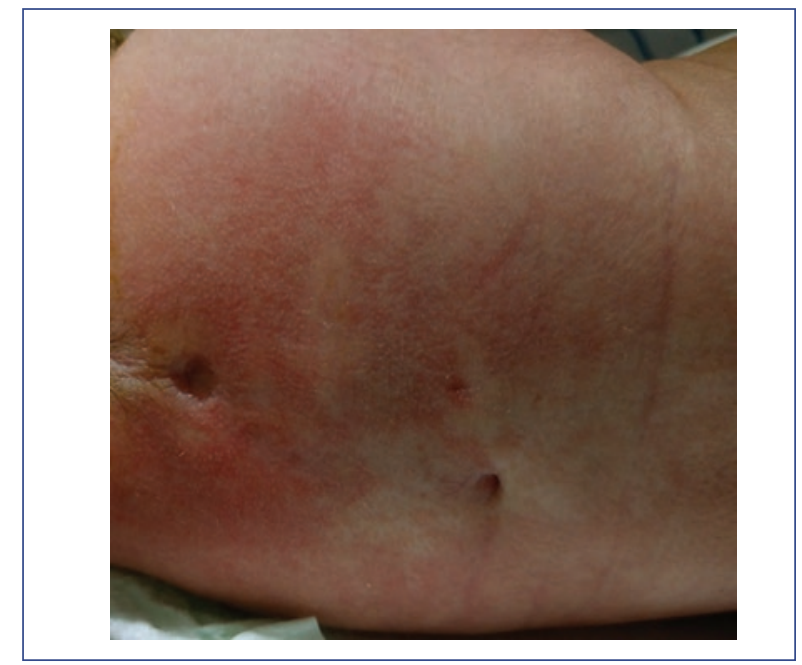

Figura 3. Herniación de la grasa lumbar.

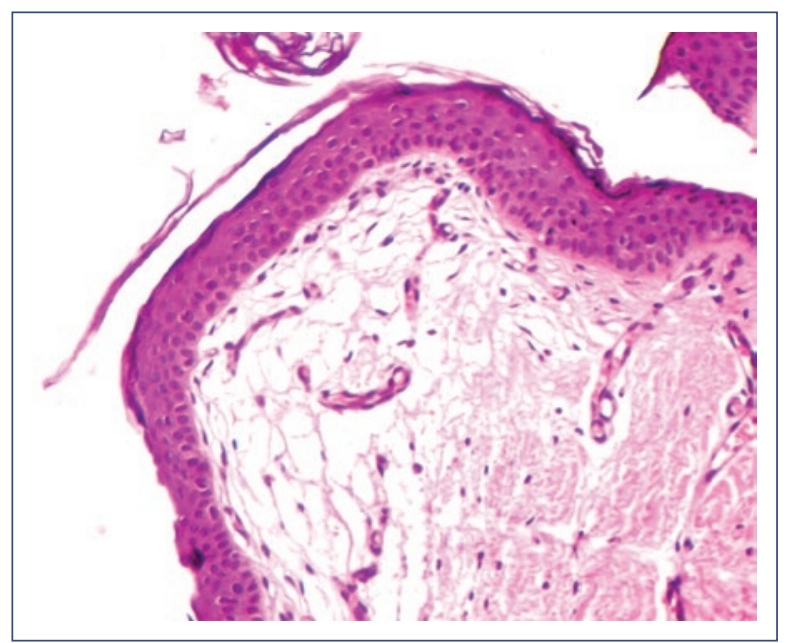

Figura 4. Biopsia de piel con atrofia de epidermis e hipoplasia de dermis (40x). La epidermis se continúa casi directamente con el tejido celular subcutáneo.

meses de vida y aumentan de manera progresiva ${ }^{1}$. Otras alteraciones cutáneas son alopecia en parches en piel cabelluda, fotosensibilidad, anormalidades de la sudoración, cambios dermatoglifos y tumores anexiales ${ }^{1}$.

En cuanto a las malformaciones sistémicas, las esqueléticas, que se presentan en un $60-80 \%$ de los casos, consisten en sindactilia, ectrodactilia, oligodactilia, defectos transversos de la extremidad (mano, codo, antebrazo, codo sin porciones restantes distales, incluyendo hemimelia y aqueiria), hipoplasia o acortamiento de huesos largos, y anormalidades 
costovertebrales como fusión de costillas, hemivértebra y vértebra en mariposa, las cuales están presentes desde el nacimiento ${ }^{1,4}$. Dentro de las manifestaciones oculares se encuentran colobomas, microftalmia, anoftalmia, catarata, nistagmo, estrabismo y anormalidades del conducto lagrimal, entre otras, presentándose en el $20 \%$ de los pacientes ${ }^{1}$. Las malformaciones dentales se han visto en más de la mitad de los casos e incluyen hipodoncia, oligodoncia, dientes supernumerarios, maloclusión, microdontia, taurodontia, dientes fusionados y displasia del esmalte dental. Entre las manifestaciones gastrointestinales se han reportado pobre ganancia ponderal, talla baja, reflujo gastroesofágico, gastroparesia, constipación y alergias alimentarias. Como manifestaciones renales y urogenitales se han reportado agenesia renal, hipoplasia renal, riñón en herradura, displasia renal quística y útero bicorne ${ }^{1,4}$. Entre las manifestaciones cardiovasculares se observan tumores cardiacos, drenaje venoso pulmonar defectuoso, dextrocardia y malformaciones como tronco arterioso ${ }^{4}$.

El diagnóstico se basa en los hallazgos clínicos (tabla 1) e histológicos; además, se cuenta con el estudio molecular del gen PORCN por análisis de secuenciación, detectando pequeñas deleciones o duplicaciones, inserciones, mutaciones sin sentido (nonsense) y de sentido erróneo (missense) $)^{1,5,7}$.

El diagnóstico diferencial incluye la enfermedad de Rothmund-Thomson (lesiones eritematosas lineales induradas con fotosensibilidad, atrofia de piel y telangiectasias, aunque la dermis es estructuralmente normal) $)^{9}$, incontinencia pigmenti, nevus lipomatoso, deleción en el cromosoma Xp22.2, síndrome de Adams Oliver y aplasia cutis congénita ${ }^{10}$.

El diagnóstico debe ser dirigido por dermatología para las lesiones de piel, tratando el dolor en los casos en que se presente, así como las lesiones erosivas, y previniendo infecciones secundarias $s^{1,3,7}$. Las lesiones cutáneas, en especial las faciales, tienen connotación estética, pero no se presenta mayor problema terapéutico; las lesiones papilomatosas de manera general son eliminadas quirúrgicamente, pero son recurrentes.
La cirugía plástica y ortopédica temprana mejora las deformidades en las extremidades.

En la actualidad se han reportado unos 300 casos de síndrome de Goltz en la literatura mundial indexada; en México, este es el tercer reporte.

\section{Responsabilidades éticas}

Protección de personas y animales. Los autores declaran que para esta investigación no se han realizado experimentos en seres humanos ni en animales.

Confidencialidad de los datos. Los autores declaran que han seguido los protocolos de su centro de trabajo sobre la publicación de datos de pacientes.

Derecho a la privacidad y consentimiento informado. Los autores han obtenido el consentimiento informado de los pacientes y/o sujetos referidos en el artículo. Este documento obra en poder del autor de correspondencia.

\section{Conflicto de intereses}

Los autores declaran no tener ningún conflicto de intereses.

\section{Bibliografía}

1. Bostwick B, Van den Veyver IB, Sutton VR. Focal dermal hypoplasia. GeneReviews ${ }^{\circledR}$. Seattle: University of Washington, Seattle; 2008. Disponible en: http://www.ncbi.nlm.nih.gov/books/NBK1543.

2. Bree AF, Grange DK, Hicks MJ, Goltz RW. Dermatologic findings of focal dermal hipoplasia (Goltz syndrome). Am J Med Genet Part C Semin Med Genet. 2016;172C:44-51.

3. Goltz RW, Peterson WC, Gorlin RJ, Ravis HG. Focal dermal hipoplasia. Arch Dermatol. 1962;86:708-17.

4. Morales ME, Ramos A, Gaxiola E, Barrera M. Hipoplasia dérmica focal (síndrome de Goltz). Rev Cent Dermatol Pascua. 2014;23:11-6.

5. Chico AB, Salene C, Juárez F, De los Ríos R, Saadi ME. Hipoplasia dérmica focal. Dermatol Argent. 2011;17:306-9.

6. Deustua S, Méndez T, Naranjo RM, Estévez Y, Escobar G. Síndrome de Goltz. Rev Cubana Oftalmol. 2016;29:735-40.

7. Acosta JC, Motta A, Prieto JC. Hipoplasia dérmica focal (síndrome de Goltz): amplia variabilidad fenotípica. Rev Argent Dermatol. 2009;90: 224-9.

8. Lawlor F, Holmes SC. Focal dermal hypoplasia syndrome in the neonate. J R Soc Med. 1989;82:165-6.

9. Temple IK, MacDowall P, Baraitser M, Artherton DJ. Focal dermal hypoplasia (Goltz syndrome). J Med Genet. 1990;27:180-7.

10. Pessoa V, Surana R. Focal termal hipoplasia. J Nat Med Assoc. 1979;71:829-31. 